\title{
correspondence
}

\section{The lipid hypothesis}

SIR,-John Rivers' article (3 November, page 2) on the lipid hypothesis may have confused readers not familiar with this subject because it conflicts with the strong consensus of recent scientific opinion. An alternative summary and explanation may be of interest.

Since 1968 no less than 19 completely independent national working parties from many different countries have between them reviewed all aspects of relevant research and reached remarkable agreement. Each $(19 / 19)$ has recommended reduction in the consumption of saturated fat either by the population as a whole (15) or by those detected by screening to be at high risk (4). Since no country has found it practicable to carry out screening on a large scale, and in any case most of those at high risk could not be detected by present means, it follows that the advice is applicable to all who wish to take reasonable precautions to preserve their health. Most (17/19) have specifically advised partial substitution of saturated by polyunsaturated fat and $17 / 19$ restricted consumption of cholesterol.

Always in human affairs, no matter how strong the majority view, a few dissident voices will be heard, and of course their viewpoints, if they have substance, must be considered. This has been done.

It is not correct to state, as Rivers does, that the DHSS (COMA) panel (Diet and Coronary Heart Disease, HMSO, 1974) and the Joint Working Party (JWP) of the Royal College of Physicians and British Cardiac Society (J. Roy. Coll. Physicians 10, 213, 1976) reached diametrically opposite conclusions. Both made the same recommendation for the whole community to reduce saturated fat. The difference was that, whereas the DHSS did not suggest what should take the place of saturated fat, on the grounds there was no proof that benefit would result, the JWP, in conformity with the consensus, did. There is of course no 'proof' because, as explained, dietary trials are impossible to carry out. However, as Professor Truswell, who is now a member of COMA, has pointed out, one cannot simply advise a reduction of something without indicating what should take its place. The two obvious sources, both of which are suitable, are polyunsaturated fat and carbohydrate (preferably unrefined) in the form of bread, cereals and potatoes. COMA had no objection to polyunsaturated fat. Consequently there are no practical differences between the two reports.

Rivers supports George Mann, a well-known heretic and none the worse for that, but his criticisms of the consensus are easily countered. The facts are formidable. As emphasised by WHO, mankind is likely to expericnce the greatest epidemic ever faced unless action is taken. In the UK, as in the USA, one man in three or four is likely to suffer from arterial discase before retirement and often long before. Coronary heart disease (CHD) is the commonest cause of death in men over 35.

The steep rise in incidence in many western countrics in recent years, the wide population variations that cannot be explained by race, the expericnce of migrants from low to high incidence countries and the changes which occurred in war indicate that the causes must largely be environmental and due to behavioural change. The evidence also indicates that, although other risk factors may contribute, radical changes in our food structure and eating habits are the fundamental cause.

The Japanese are a modern, industrial, stressful, heavily-smoking and unusually hypertensive society, but have little atheromatous disease. This can be explained by their low (normal) blood lipid levels, related to their habitual diet. If Japanese migrate to the USA. however, as they have done in large numbers, and changc, in particular, their food habits, the blood cholesterol levels rise, arterial disease develops and in due course they have a similar incidence of CHD to their host country. In recent years similar dietary changes have been occurring in Japan, with the expected results.

The links between diet, plasma cholesterol concentrations, atherosclerosis and CHD are immensely strong. They are based on epidemiological correlations, clinical observations, pathological changes, the vast International Atherosclerosis Project which correlates diet, blood lipids and arterial changes, laboratory studies on mechanisms and on experimental work. If man's nearest relatives, the non-human primates, are given a similar human diet, they develop a similar rise in blood cholesterol and, in due course, similar arterial changes with similar complications. Encouragingly, if those who have developed arterial disease return to their natural dict, considerable regression can occur.

The final link by controlled dietary studies in man is impossible to forgc owing to the practical difficulties. It is not correct to say that dietary studies are being carried out that could bring final proof. Mann makes much of inconclusive dietary studies, but it is now appreciated that although the matter had to be put to the test (and most think the results were encouraging), absolute proof cannot be obtained. Under these circumstances, action has to be based on the best available evidence.

Rivers refers to dietary studies within populations and refers to Michigan as an example. In affiuent communities, however, most penple habitually consume a similar rich diet, with relatively high serum cholesterol levels compared with low incidence countries. The very high correlations which have been obtained are from studies in countries with widely different habits, and they are very convincing.

It is unfortunate that Rivers should again bring up the cancer scare. This was raised some nine years ago in an elderly population being studied in Los Angeles. The matter was immediately investigated but not confirmed either in that study or in any other. As Heady, from the London School of Hygiene and Tropical Medicine, wrote in the British Medical Journal (1, 115, 1974), "the case is not merely unconvincing, it does not stand examination".

The unsaturated vegetablc oils now being recommended are consumed in similar amounts by many European populations with a very low mortality from CHD and cancer. They are also consumed in large amounts in South Russia. The question of trans unsaturated fatty acids has also been very thoroughly studied. No harmful effects have been found experimentally and they have been incorporated in margarines for about 70 years without untoward effects. Their concentration is higher in butter than in

polyunsaturated margarine.

It is also incorrect to state that over $90^{\circ}$ " , of body cholesterol is synthesised. The body synthesises sufficient cholesterol for all its needs and all dietary cholesterol is surplus to requirements. However, isotope studies have shown that this amounts on average to about $25 \%$ of plasma cholesterol, and in some it is more (Kaplan, J. A. et al., Arch. Path. 76, 359, 1963). This is a substantial 'extra'. There is considerable individual variability, but it could be critical. Another important fact is that in response to cholesterol consumption, tissue concentrations may rise steeply with little or no change in the plasma.

The permeability of the arterial wall is an important variable factor, but unfortunately cannot be studied by simple laboratory tests.

As regards the Masai, the relevant fact is that they have very low serum cholesterol levels which would account for their freedom from CHD. As Mann himself showed, any atheroma present is mild and, even if the vessels had not become widened, there would be no obstruction.

As regards exercise, the East Finns, who have long had the highest serum cholesterol levels in the world and the highest mortality from CHD, habitually undertake more exercise than the Masai. If the diet is faulty, regular strenuous exercise is clearly not protective. This is not to deny the value of exercise in reducing the risk of CHD. There is some evidence of this even in Finland.

Doubtless new information on mechanisms will be obtained by future research, but it is very unlikely it will influence the need to correct some of the radical changes man has made in his food structurc and eating habits in recent years. The principal problems are not what to do or how best it could be done, but those of motivating the many concerned.

Your faithfully, R. W. D. TURNER

University of Edinburgh, UK 